\title{
A community based seismic system for obtaining regional and local seismic data of strategic importance
}

\author{
J. Wesseloo Australian Centre for Geomechanics, The University of Western Australia, Australia
}

M.R. Hudyma School of Engineering, Laurentian University, Canada

P. Harris Australian Centre for Geomechanics, The University of Western Australia, Australia

\begin{abstract}
In many parts of the world, natural and mining induced seismicity impacts on mining risk. The Australian Centre for Geomechanics (ACG) developed a Regional Seismic Network (RSN) to provide local and regional seismic monitoring that enable the detection and location of larger mine induced seismic events, as well as smaller earthquakes occurring outside of the mine volume. The system is flexible and consists of easily sourced "off-the-shelf" components. The system is easily implemented in new locations and the data and processing of the events are accessible through a normal internet browser.
\end{abstract}

\section{Introduction}

In many parts of the world natural and mining induced seismicity impacts on mine design mining risk. This geotechnical risk may take the form of, for example, higher probabilities of slope failure under seismic excitation, liquefaction of tailings dams or underground backfill, rockfall due to the shaking effect of a nearby natural earthquake, and damage to buildings.

Uncertainties regarding regional and mining induced seismicity impacts on management decisions. Strategic decisions regarding infrastructure and mine design will benefit from recorded seismic data from a regional and local seismic system as this allows for the quantification of the seismic regime.

Generally speaking, seismic hazard data is well established for earthquake prone areas in the world. However, the focus of earthquake seismology is generally on the large natural earthquakes and the areas where these occur. As a result, data of smaller earthquakes are often not available. As an example, Figure 1 shows the seismic system sensitivity for the Australian National Network (Sagar and Leonard, 2007). The value Mc (Magnitude of completeness), refers to the smallest magnitude event that can consistently be recorded by the network. In the Kalgooorlie mining area in WA, the Mc appears to be about 2.75 on the Richter scale.

Added to the problem of sensitivity is also the accuracy of the locations. Due to the large distances between the seismic sensors, the location accuracy of the event epicentres can be quite large. This is not a problem within the scale of earthquake seismology, but introduces a high degree of uncertainty if the intention is to use the data on a smaller local or regional scale.

The national networks are focussed as a country-wide assessment of seismic hazard and only record large events at a location accuracy too coarse for local use. Localised targeted networks are necessary to obtain data for events below the national network sensitivity and to improve the location accuracy for events.

The ACG has developed a community based seismic system (RSN). This paper discusses the technical aspects of the system whilst its use is discussed in an accompanying paper by Hudyma and Wesseloo (2011). 


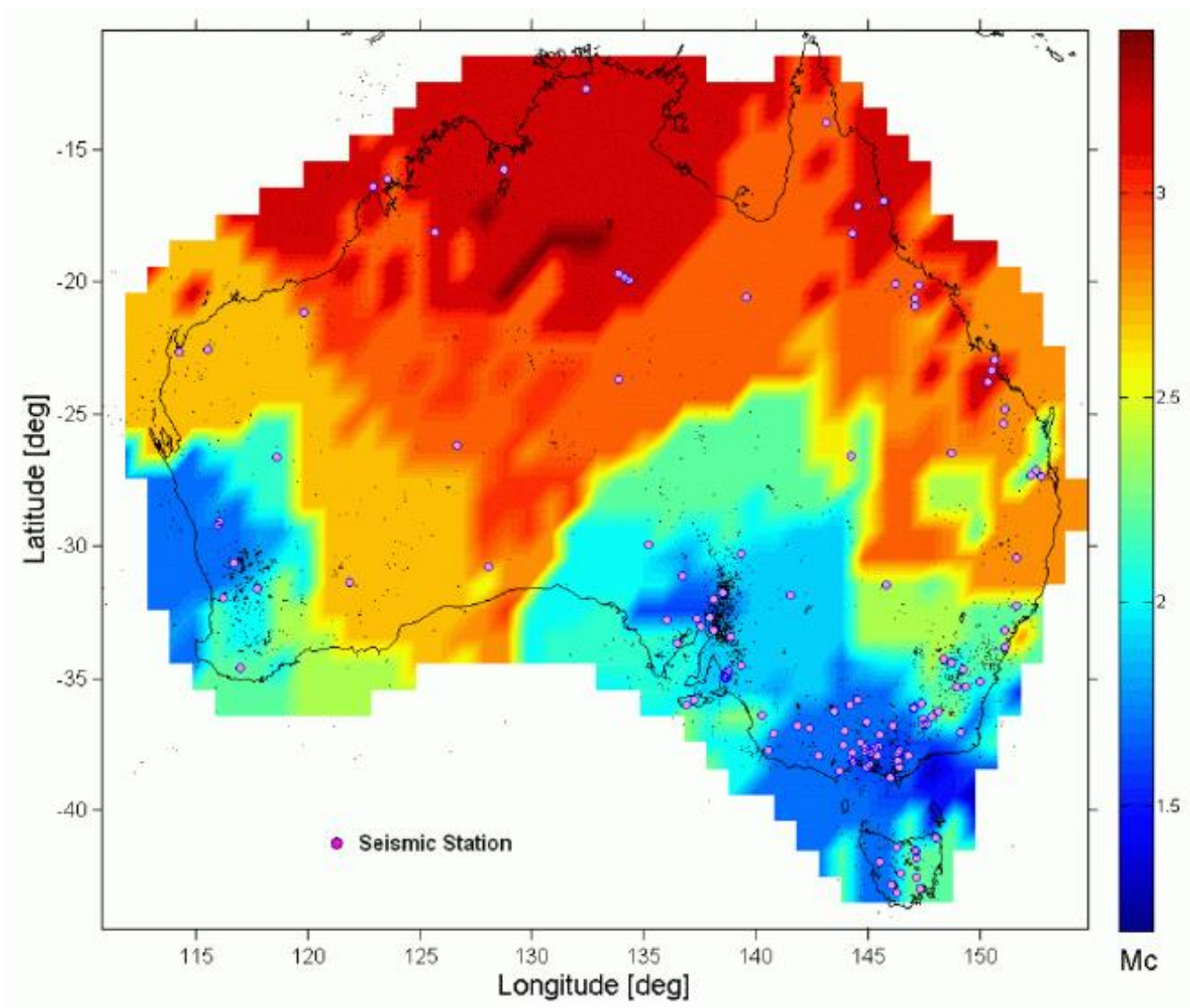

Figure 1 Seismic system sensitivity for Australian National Network (Sagar and Leonard, 2007)

\section{$2 \quad$ ACG RSN}

In principle, the ACG RSN is a public seismic network (PSN). Several PSN's exist around the world and normally consist of collaboration among amateur and/or professional seismologists sponsoring and maintaining sensors and sharing data from these sites to form, through collaboration, a seismic network.

\section{1 Aim of the ACG RSN}

The general aim of the ACG RSN is to provide a local and regional seismic monitoring to enable the detection and location of large mine induced seismic events as well as smaller earthquakes occurring outside of the mine volume. The network was developed with the following key attributes in mind:

- low cost

- quick and easy addition of new sites

- provide access to data and processing of data to all stakeholders.

The ACG RSN consists of several regional and local seismic networks each having its own focus, some of which being:

- A backup system to locate large mining induced seismic events.

- To provide an independent check on the magnitude of large events recorded by the mine's microseismic system.

- To detect and locate natural seismic events (as opposed to mine induced seismic events) inside the mining region but outside the mining areas. 
One of the local RSN's was installed to comply with a government requirement to gather and provide the government agency with access to ground motion data around the nearby town. The information included any ground motions originating from the mine such as blasts and mine induced seismic events. The ACG RSN provided an easy and convenient solution to comply with this requirement.

The ACG currently hosts several regional networks: Leinster and Kalgoorlie-Kambalda areas in Western Australia; and Sudbury in Canada.

Local networks are installed at a Tasmanian mine in Tasmania; and a Broken Hill mine in South Australia.

\section{2 Components of the network}

Any seismic system essentially consists of four components, namely:

- sensors for detecting vibration

- data recording infrastructure

- data transfer infrastructure

- infrastructure for processing wave data in order to extract location and other parameters from the waveforms.

The ACG RSN makes use of an analogue to digital signal convertor (digitiser) and computer at each sensor to record and store data. Data is transferred to the ACG RSN server using internet communications and users access the data and perform data processing on the ACG RSN server through any web browser.

Utilising a web interface for user access to the data and processing routines has the important advantage that internet access is the only restriction to data access. Processing of data can therefore be done from any computer with internet access.

Figure 2 illustrates the components of the ACG RSN. The different components will be discussed in more detail in the following paragraphs.

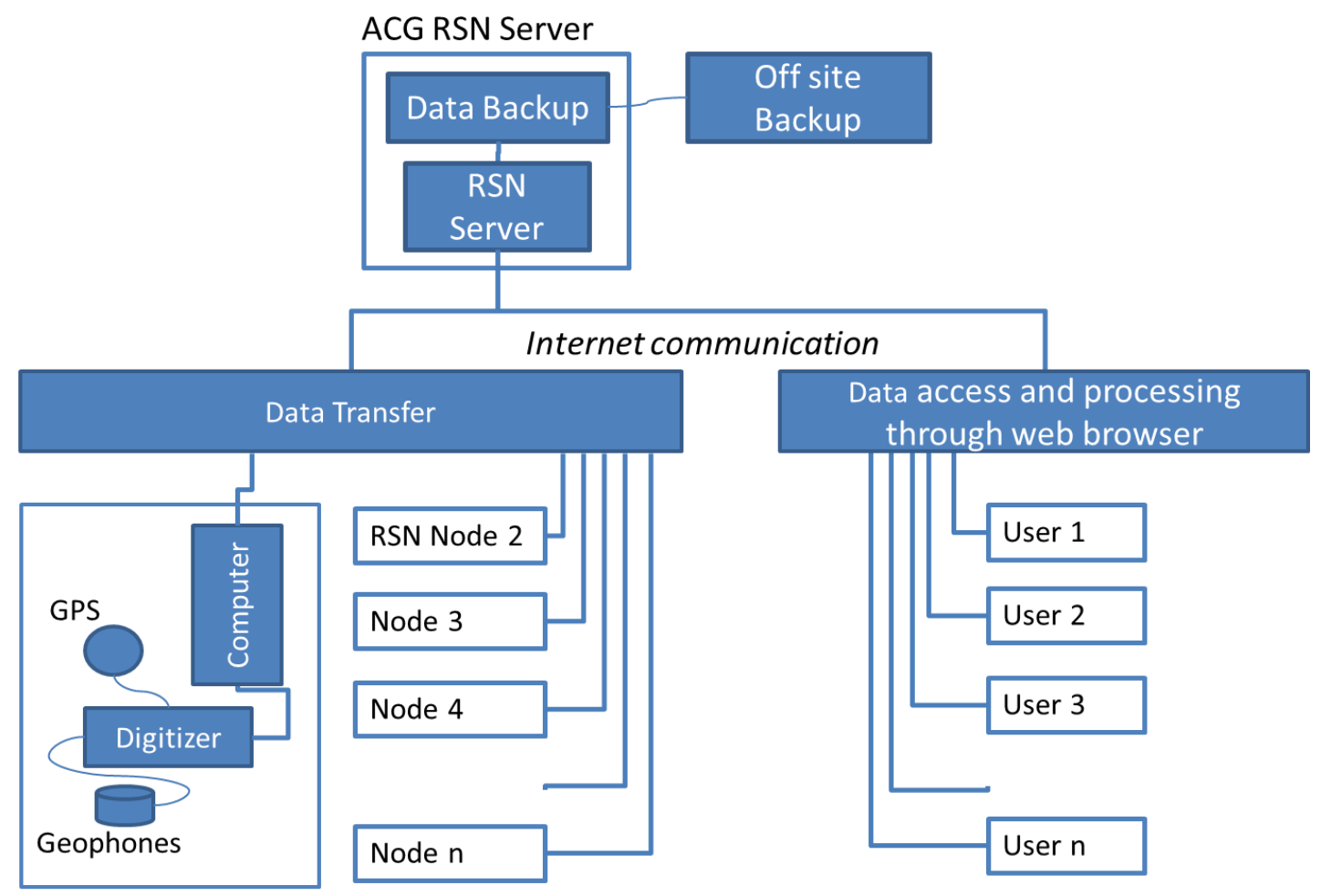

RSN Node 1

Figure 2 Illustration of the ACG RSN components 


\section{2.1 Sensors}

The ACG regional seismic network uses $4.5 \mathrm{~Hz}$ triaxial geophones installed on surface. These geophones consist of three orthogonal sensors that record the vibrations in three orthogonal directions, housed in a boat with a diameter of $12 \mathrm{~cm}$ and height of $7.5 \mathrm{~cm}$. The geophone boats normally used in the RSN are shown in Figure 3. There is, however, no requirement for any specific sensor and different types of sensors can be used.

The geophones are connected to a digitiser with co-axial cables. Co-axial cable lengths of several hundred metres have been used successfully.

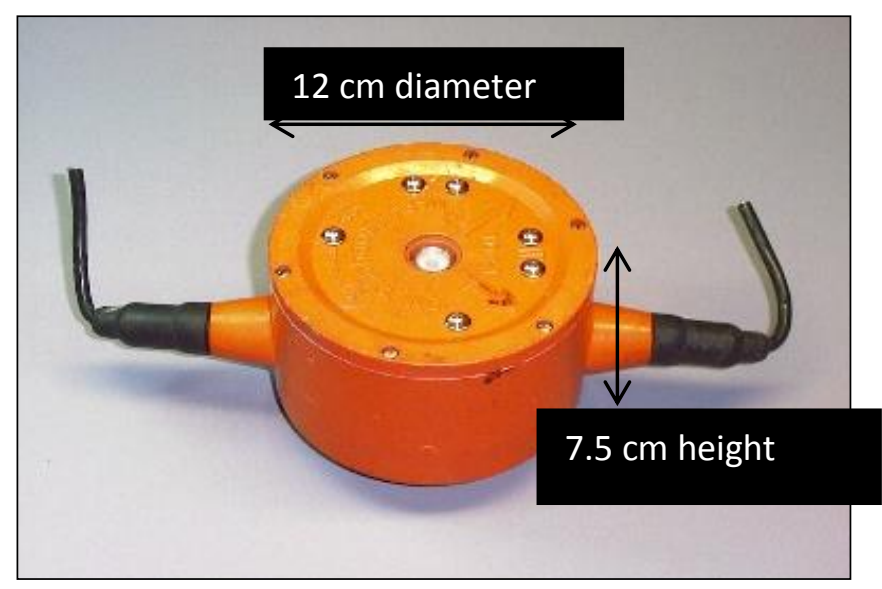

Figure 3 Triaxial geophones to be installed onsite

\subsection{Digitising and recording}

\subsubsection{Digitiser}

The sensor is connected to a digitiser that transfers the analogue signal from the geophones to a digital signal by sampling the data at a high frequency. The original digitiser units that were used in the older RSN sites have a sample rate of $200 \mathrm{~Hz}$ while newer sites have a sample rate of $400 \mathrm{~Hz}$. Digitisers that can sample at a higher rate can also be used should the need arise.

\section{2.2. 2 GPS}

The digitisers are connected to a GPS (Figure 4). This allows the digitiser to record the time of each sample to an accuracy of about 2 milliseconds and data from different nodes to be processed on the same absolute time basis. Higher location accuracy can be obtained when using absolute time processing. Epicentre location can still be obtained without GPS time, provided that the relative arrival times of both the primary and secondary waves for each of the nodes are available.

Using GPS time has the added advantage that the data from different networks can be integrated on an absolute time basis as long as the different systems all use GPS time. 


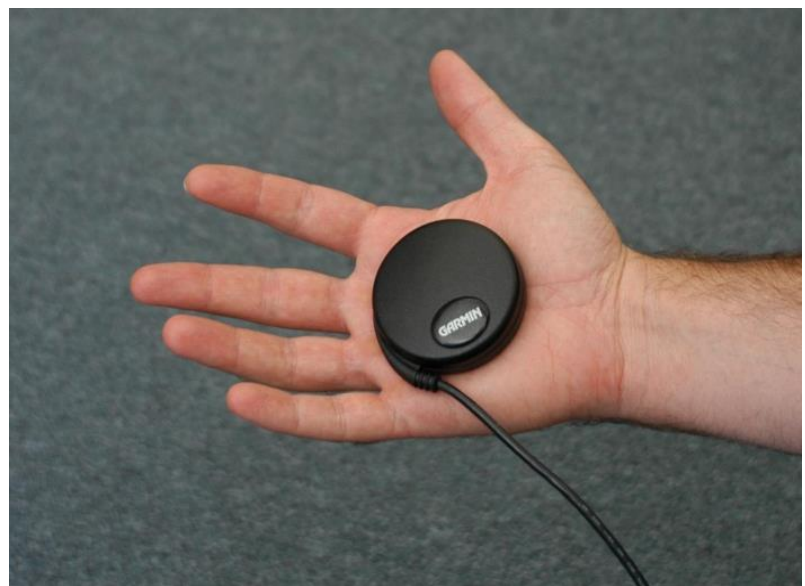

Figure 4 The GPS unit used at the sites

\subsubsection{Computer}

Each digitiser is connected to a personal computer that stores the data and communicates with the ACG RSN server. Normal desktop computers are used where access to buildings and electricity are available. These computers do little processing and the hardware requirements are low.

Remote access software is installed on each of the computers to allow for troubleshooting should the site experience problems.

Most of the RSN participants are mine sites, through their sponsorship of the ACG's Mine Seismicity and Rockburst Risk Management Project. The geophones and GPS are placed outside the building with the cables running inside the building to connect to the PC and digitiser. The computers are connected to the mine's local area network (LAN) with access to the internet.

\section{2. 2. 4 Data communication}

Data at each of the RSN nodes are recorded on a continuous basis at a sampling rate of at least $200 \mathrm{~Hz}$ and results in about $500 \mathrm{MB}$ of data per month. In order to limit the amount of internet traffic from each of these sites, lower quality data at $50 \mathrm{~Hz}$ are uploaded on a continuous basis to the ACG RSN server. This data is used to run triggering algorithms and preliminary processing. Whenever an event is defined by a user, the ACG RSN server requests the related high quality data from the site computer. Processing of the seismic events is then performed using the high quality data.

Data communication is performed through normal internet access. A program uploads seismic data through the site's existing internet connection, usually without the need for adjusting firewalls and can be done through standard internet proxy servers.

\subsubsection{Web based user interface}

Data access and processing is provided through a web interface with the major advantages that data access and event processing can be performed from any computer with internet access.

The web page interface provides the user with full processing capability for events, such as:

- Full navigation in time and amplitude.

- Picking phase arrivals, including and brackets with uncertainty windows.

- Capability of jumping to previously processed events and possible events identified by the triggering algorithm.

- Navigate through time viewing the continuous waveform data uploaded for each site (Figure 5). 


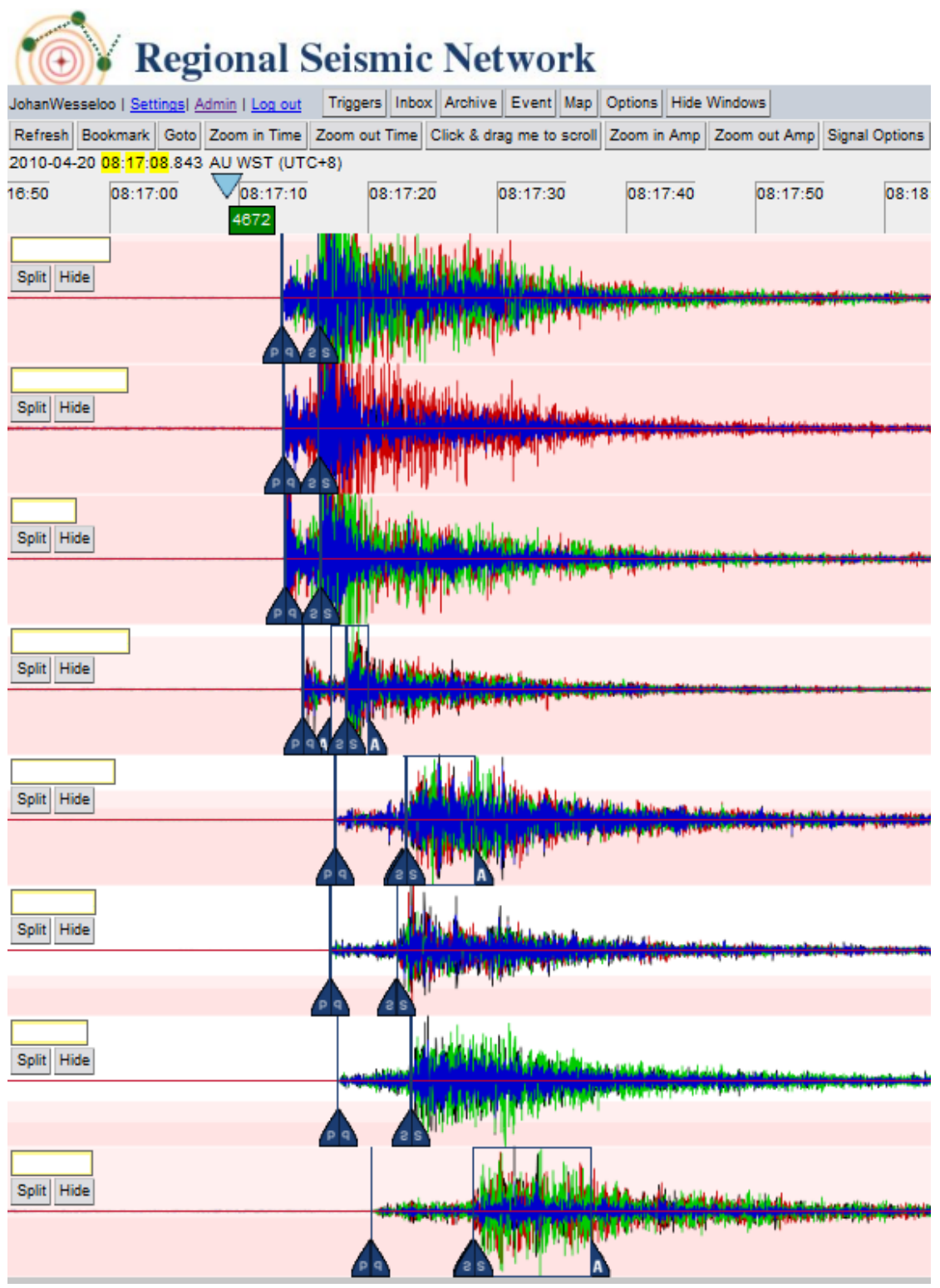

Figure 5 RSN web interface for accessing and processing data from the network

Based on the phase picks provided by the user, the RSN locates the event using a probabilistic, non-linear, global-search algorithm (Lomax et al., 2000). The result is plotted on a Google Maps image as shown in Figure 6. The algorithm uses a probabilistic method and assigns probabilities to different locations. These probabilities are coloured from green, being least likely to red being the most likely, with the event location assumed to be at the location with the highest probability assigned to it (Figure 6). 

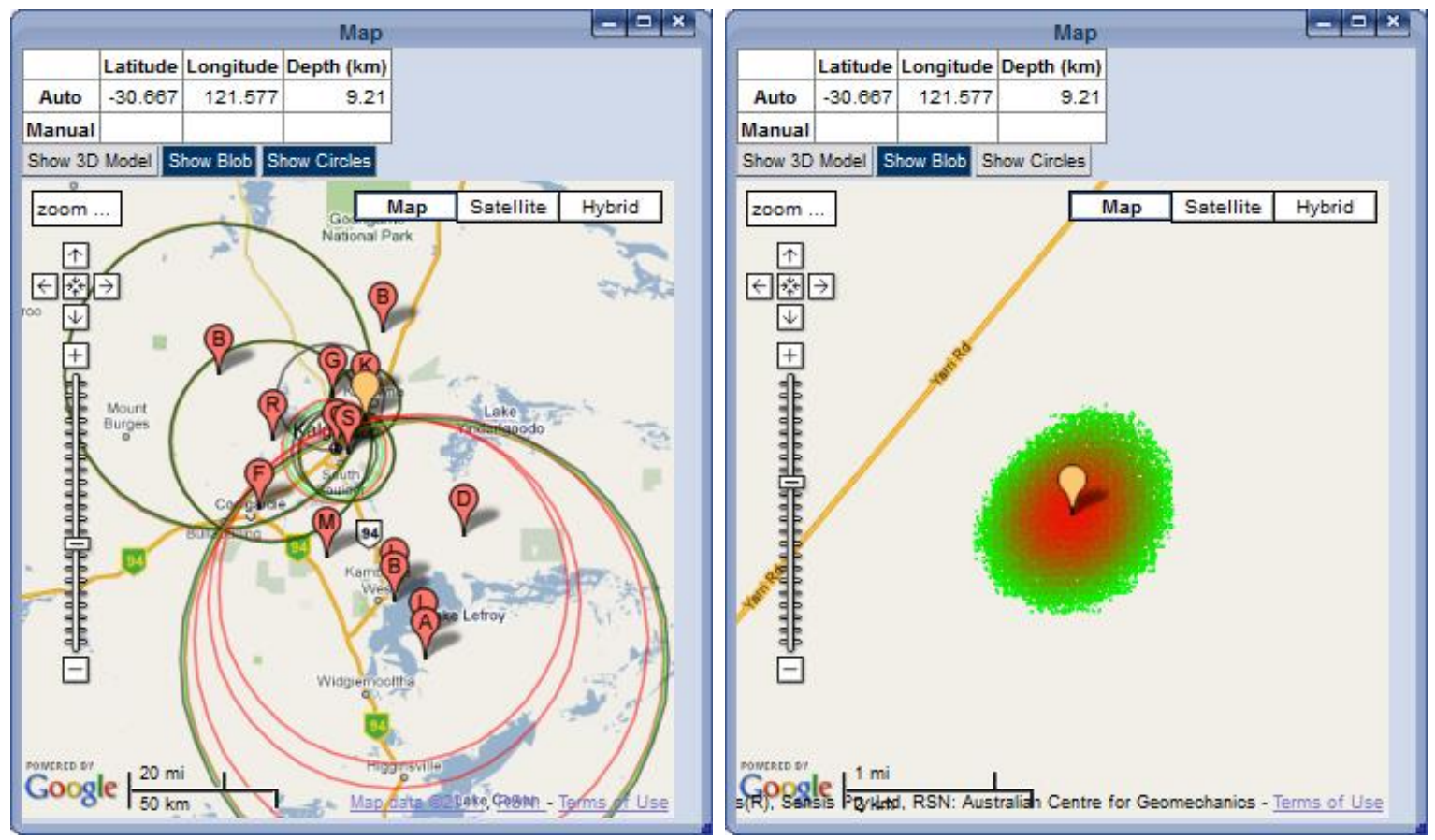

Figure 6 Event location images produced by the RSN website

\section{3 Remote sites}

Most of the RSN participants are mine sites with the geophones and GPS's placed outside a mine site building and the cables running inside the building to connect to the digitiser and PC that is connected to the mine's LAN with access to the internet.

The basic requirement for an RSN site is the ability to establish communications to the internet and electricity to power the computer and digitiser. This provides for flexibility in the site setup. Figure 7 shows the site setup for one of the more remote sites. In this particular case, a normal laptop computer is used and the instrumentation was mounted on an existing electrical cabinet for a nearby pump station with data being uploaded in real-time via a Telstra Next-G wireless modem. In another site in the same network, electricity is provided through solar panels with the rest of the setup being similar to that described above. 


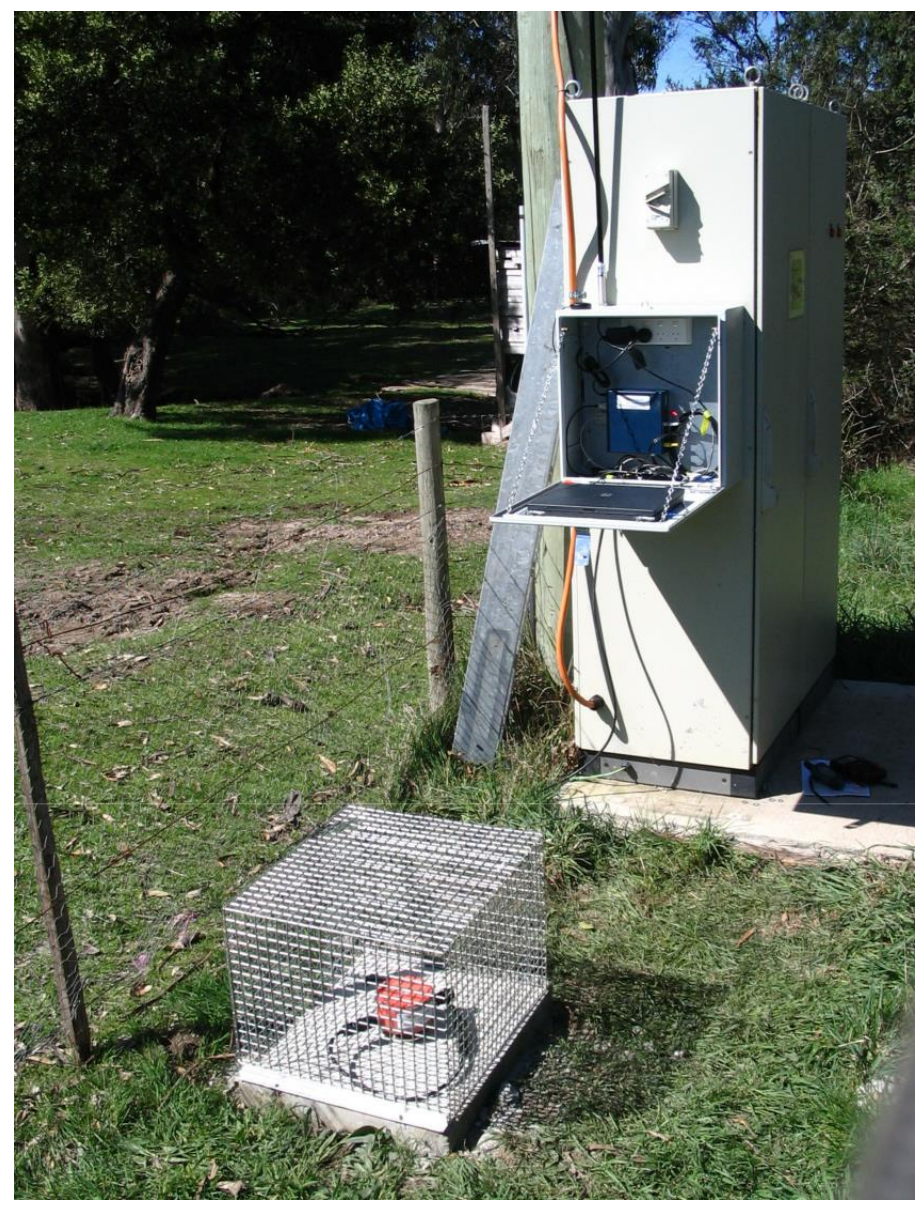

Figure 7 One of the more remote stations using a Telstra Next-G wireless modem to communicate to the RSN server

From processed and located events, the epicentre distance and peak ground motion parameters, namely, peak particle velocity, and peak particle displacement are available. An estimate of the Richter Magnitude of the seismic event is obtained using the following relation developed for Australia (Gaull and Gregson, 1991):

$$
M_{R}=\log (A \cdot 2050)+1.137 \cdot \log (R)+0.000657 \cdot R+0.66+S_{i}
$$

where:

A $=$ peak displacement $(\mathrm{mm})$.

$\mathrm{S}_{\mathrm{i}}=$ a correction for each site to address the local site effects.

$\mathrm{R}=\quad$ the distance between the hypocentre and the sensor.

This relation has been found to work reasonably well, even without calibration for the site effects a reasonable estimate of the magnitudes can be obtained. However, better and more consistent results can be obtained when networks are calibrated to account for local site effects and regional changes in the geological environment. Internal and external calibration of the seismic system can be performed.

\section{1 Internal calibration}

Internal calibration refers to the relative calibration of each of the different sites to each other for the purpose of reducing variations in the results obtained from different sensors or subsets of sensors. No data external to the RSN itself is necessary to do internal calibration. 
The internal calibration process is illustrated in Figure 8. Different sites respond differently due to differences in the local site conditions, some sites such as Site 2 and 5 over register and some like Site 4 under register. In the uncalibrated case, the magnitude is taken as the mean value obtained from each of the sensors. An event only registered by sensors 3, 4, and 5 will be underestimated while an event registered by sensors 1,2 and 3 will be overestimated. The internal calibration minimises the variation between sensors by compensation for the amount of under- or over-registration relative to the mean value obtained from all the sensors. Internal calibration can be performed with limited data and refined as more data is obtained. Events in this case could be waves from either seismic or blast occurrences.

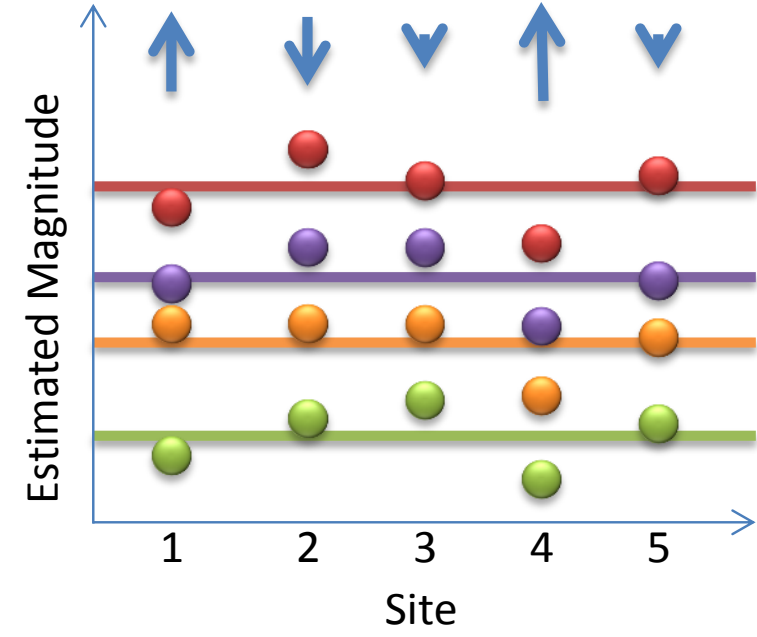

Uncalibrated

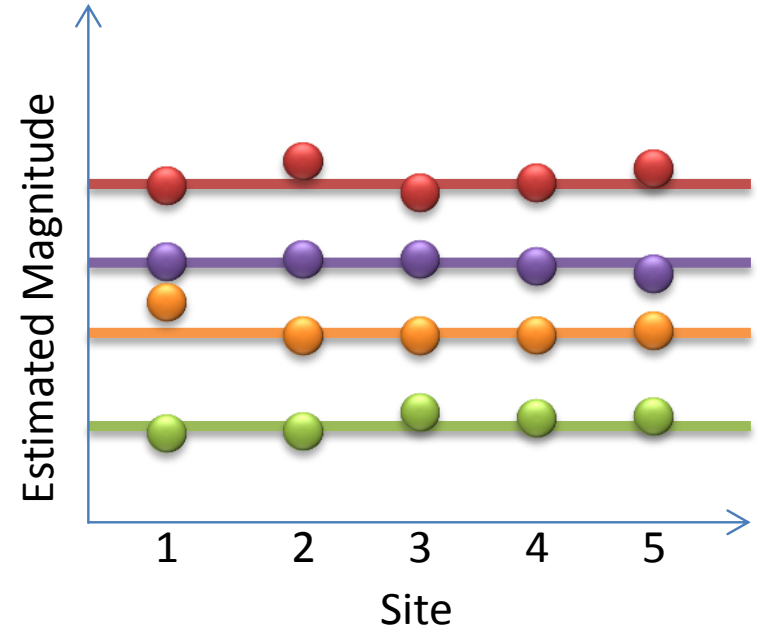

After internal calibration

Figure 8 Conceptual illustration of the internal calibration process

\section{2 External calibration}

Data from other systems can be used to calibrate the internally calibrated system with other systems. An example of this is the calibration of the RSN to mine site local systems and the Geoscience Australia (GA) national network data. Internal calibration will be performed over the full range of magnitudes recorded by the system while GA data typically only contains the largest events that are detected by the seismic system. An internally calibrated system needs fewer external events to enable calibration of the system to an external source.

The external calibration process is illustrated in Figure 9. After internal calibration is performed, external calibration can be performed by applying a correction to the mean magnitude value obtained from the network to represent the reference values. For this, events recorded by both the RSN and a reference system (for example the GA national network, or the mine's microseismic network) are necessary. 


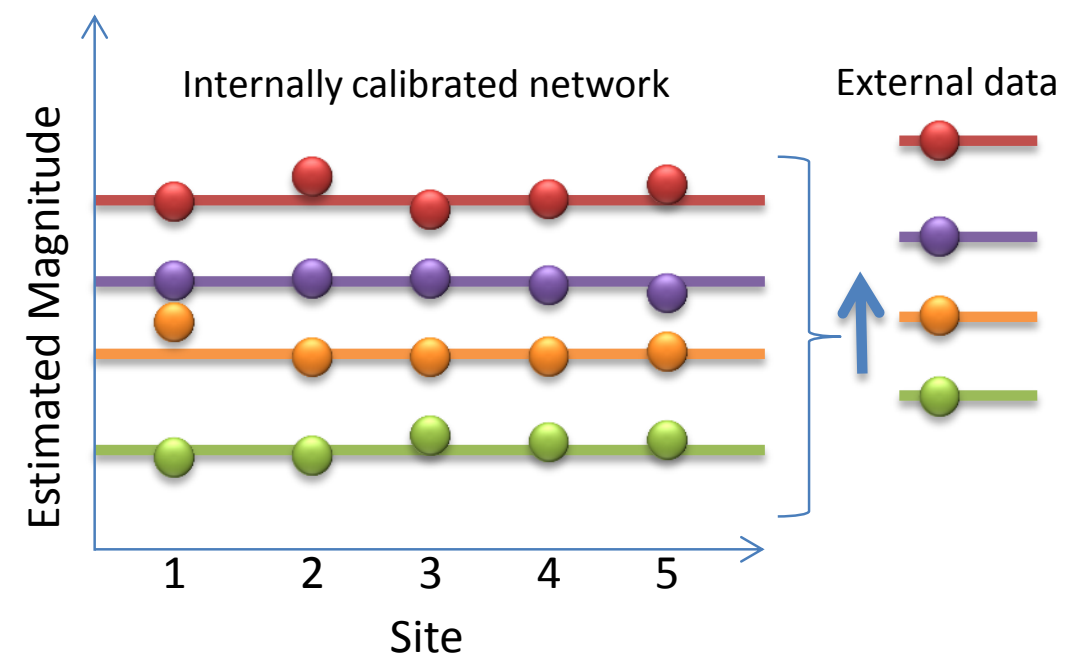

Figure 9 Conceptual illustration of the external calibration process

\section{Conclusion}

The Australian Centre for Geomechanics has developed a Regional Seismic Network infrastructure that can be used to design a regional or local seismic network easily and at low cost. The system is flexible and consists of easily sourced and "off-the-shelf" components. The system provides the opportunity to record data about regional and local seismic activity that can impact negatively on the mining operations.

\section{Acknow l edgements}

The authors wish to acknowledge the contributions of Dan Heal and Vic Dent in the original development of the system. The ACG RSN was developed under Phase 3 of the Mine Seismicity and Rockburst Risk Management (MSRRM) Project. The ACG would like to sincerely thank the following sponsoring companies Phase 3 of the MSRRM project: Minerals and Energy Research Institute of Western Australia (MERIWA), Barrick Gold of Australia, Noilsk Nickel (formerly LionOre Australia Ltd), BHP Billiton Nickel West, Perilya Limited, Lightning Nickel (Independence Group NL), LKAB Sweden, Kirkland Lake Gold, Agnico-Eagle Mines Ltd, Kalgoorlie Consolidated Gold Mines, Allstate Explorations NL (Beaconsfield Gold NL), Newcrest Cadia Valley Operations (Ridgeway), Harmony Mt Magnet Gold, Xstrata Copper (Kidd Mine), Oxiana Limited (Golden Grove), Newmont Asia Pacific, AngloGold Ashanti Australia, Codelco Chile (El Teniente), Xstrata Zinc (Brunswick Mining and Smelting), Reliance Nickel P/L (Consolidated Minerals Group), Xstrata Nickel (Cosmos Nickel Project - Sir Samuel Mines) and Gold Fields Australia (St Ives Gold and Agnew Gold).

\section{References}

Guall, B.A. and Gregson, P.J. (1991) Australian Journal of Earth Science, Vol. 38, pp. 251-260.

Hudyma, M.R. and Wesseloo, J. (2011) Strategic and tactical use of a community based regional seismic monitoring system, in Proceedings from the Fourth International Seminar on Strategic versus Tactical Approaches in Mining, Y. Potvin (ed), Perth Australia, 8-10 November 2011, pp. 169-178.

Lomax, A., Virieux, J., Volant, P. and Berge, C. (2000) Probabilistic earthquake location in 3D and layered models: Introduction of a Metropolis-Gibbs method and comparison with linear locations, in Advances in Seismic Event Location, C.H. Thurber and N. Rabinowitz (eds), Kluwer, Amsterdam, pp. 101-134.

Sagar, S. and Leonard, M. (2007) Mapping the Magnitude of Completeness of the Australian Earthquake Catalogue, in Proceedings of Australian Earthquake Engineering Society, Wollongong, Australia. 